\title{
1. Introduction and Overview
}

Starting from the early 1990 s support for 'sustainable development' (henceforth: SD) has become very widespread. At the Rio summit in 1992 the vast majority of nation-states have formally committed themselves to SD in signing Agenda 21 (UNCED 1992) - a commitment renewed at the 2002 World Summit on Sustainable Development in Johannesburg. Especially since then, there has been hardly any politician, academic or businessperson who does not call for making development sustainable. In some sense this is not surprising: SD is like freedom or peace - that is, something to which no reasonable person would overtly object. Development always sounds good and that it has to be sustainable seems self-evident.

In this book two economic paradigms of SD - 'weak sustainability' and 'strong sustainability' - will be analysed with the objective of exploring their limits. 'Weak sustainability' (henceforth: WS) is based upon the pioneering work of two neoclassical economists: Robert Solow (1974a, 1974c, 1986, 1993a, 1993b), a Nobel Laureate, and John Hartwick (1977, 1978a, 1978b, $1990,1993)$, a famous resource economist. WS can be interpreted as an extension to neoclassical welfare economics. It is based on the belief that what matters for future generations is only the total aggregate stock of 'manmade', human and 'natural' capital ${ }^{2}$ (and possibly other forms of capital as well), but not natural capital as such. Loosely speaking, according to WS, it does not matter whether the current generation uses up non-renewable resources or dumps $\mathrm{CO}_{2}$ in the atmosphere as long as enough machineries, roads and ports as well as schools and universities are built in compensation. Because natural capital is regarded as being essentially substitutable in the production of consumption goods and as a direct provider of utility, I call WS the 'substitutability paradigm'.

In opposition to WS stands 'strong sustainability' (henceforth: SS). While WS is a relatively clear paradigm in that it builds upon a wellestablished core of neoclassical welfare economics, SS is not. It is more difficult to define SS and pin down its implications, as many different scholars have contributed their own views on what SS should be. However, the essence of SS is that natural capital is regarded as non-substitutable, in the production of consumption goods ('source' side of the economy), in its capacity to absorb pollution 
('sink' side of the economy) and as a direct provider of utility in the form of environmental amenities Hence, I call SS the 'non-substitutability paradigm'.

The objective of this book is to explore the limits of the two opposing paradigms of sustainability. In particular, it will assess whether either paradigm can provide a clear course of action and a measure ${ }^{3}$ for whether sustainability is achieved or not. The book is thus an exercise in exploring the limits of what we can know about the requirements of sustainability.

The book is structured as follows. Chapter 2 discusses conceptual, ethical and paradigmatic issues of SD. The definitions, assumptions and the methodology of the analysis in the book are laid down. Then some arguments are presented which make SD plausible as an ethical choice. A kind of timeinconsistency problem of SD is discussed which results from the fact that the current generation can only commit itself, but not coming generations, to SD. Finally, two misunderstandings about what sustainability requires are corrected. It is shown that SD neither locks society into eternal poverty if it is poorly endowed at the start nor demands the choice of greatly inferior utility paths. These ethical issues of SD are dealt with before a distinction is made between WS and SS, because they apply to both paradigms equally.

Next in Chapter 2 the two opposing weak and strong paradigms of sustainability are characterised. It is shown that WS can be interpreted as an extension to neoclassical welfare economics with the additional requirement of non-declining utility over time. The implications of the substitutability assumptions are explained. As regards SS, two differing possible interpretations are given. One calls for preserving natural capital in value terms, ${ }^{4}$ the other one calls for preserving the physical stocks of certain forms of so-called critical natural capital. The implications of the non-substitutability assumption are explained.

Finally, Chapter 2 stresses the importance of the substitutability assumption using climate change as a case study. It is shown that cost-benefit analysis, as exemplified by the approach taken by Nordhaus (1991a, 1994, 2008), comes to the conclusion that only minor emission cut-backs are efficient and therefore optimal, unless the discount rate used is very low as in the Stern (2007) Review. The predominant critique of Nordhaus has concentrated on the rate of discount to be used. I argue that the more important issue is Nordhaus's implicit assumption of substitutability of natural capital. If one accepts the substitutability assumption, then it is very questionable whether one can make a very persuasive case for using a relatively low discount rate. I therefore argue that substitutability should be the main issue in dispute, not discounting.

Chapter 3 analyses the validity of the basic assumptions of both paradigms. As mentioned, WS regards natural capital as being essentially substitutable both in the production of consumption goods and as a more direct provider of 
utility. SS, in contrast, regards natural capital as being essentially nonsubstitutable. Chapter 3 first examines theoretical and empirical evidence on the availability of natural resources for the production of consumption goods. Four propositions of resource optimism are stated and critically assessed. These propositions imply that a natural resource can either be substituted with another resource or man-made capital, or that the feedback mechanisms triggered by rising resource prices and technical progress will work to overcome any apparent constraint. Second, it discusses whether future generations can be compensated for long-term environmental degradation. It argues that an answer to this question must be speculative to some extent as we cannot know the preferences of future generations. It also argues that there are good reasons against both extreme positions; that is, neither unlimited substitutability nor perfect non-substitutability of natural capital as a provider of utility seems reasonable. As will be explained in Section 2.3.1, p. 21, WS tends to be rather optimistic about the environmental consequences of economic growth, however. Therefore it has to rely less on the assumption that natural capital is substitutable as a direct provider of utility. In other words, it has to rely less on the assumption that increased consumption opportunities can compensate future generations for the loss of natural capital in the form of long-term environmental degradation. Chapter 3 therefore analyses thirdly the link between economic growth and environmental degradation. The theoretical case both in favour of environmental optimism, which suggests economic growth is good for the environment at least over the long run, and environmental pessimism, which contends the opposite, are put forward. However, since the likely environmental consequences of future economic growth cannot be solved theoretically, the existing empirical evidence on this question is examined as well.

In short, Chapter 3 comes to the conclusion that neither paradigm of sustainability is falsifiable. As is so often the case for extra-paradigmatic disagreements, support for one paradigm or the other depends much on basic beliefs (here about possibilities of substitution and technical progress) which are non-falsifiable and can therefore not be conclusively decided. The book offers an alternative explanation to that of Norton (1995) who argues that the debate between proponents of weak and strong sustainability cannot be resolved because there is no agreement on the scope of the true subject matter nor a consensually accepted methodology. Chapter 3 argues that it would still be impossible to resolve the debate even if there was agreement on the subject matter and a consensually accepted methodology.

That, strictly speaking, both paradigms of sustainability are non-falsifiable does not imply of course that scientific research cannot help in informing policy-making for sustainability. Chapter 4 takes up the discussion where it ended in Chapter 3 and argues that a combination of the distinctive features of 
natural capital with the prevalence of risk, uncertainty and ignorance make a persuasive case for the preservation of certain forms of natural capital that provide basic life-support functions. It argues that, in principle, there are good reasons for the protection of global life-support resources such as biodiversity, the ozone layer and the global climate as well as the restriction of the accumulation of pollutants, unsustainable harvesting and soil erosion. Conversely, no explicit protection policy for non-renewable resources used in the production of consumption goods seems warranted. In essence, therefore, Chapter 4 argues that there is more support for WS with regard to the 'source' side of the economy, while there is more support for SS with regard to the 'sink' side of the economy and with regard to natural capital as a direct provider of utility in the form of environmental amenities

Chapter 4 discusses various ways of coping with risk, uncertainty and ignorance, from the traditional neoclassical economic approach to alternatives in the form of the precautionary principle and safe minimum standards (SMS). The traditional economic approach deals with risk, uncertainty and ignorance via including option and quasi-option values into environmental valuation. Such an approach is helpful, but critics argue insufficient. The alternatives have their problems as well and these are discussed at some length for SMS in particular. A further question is how much cost society should be willing to incur in order to preserve certain forms of natural capital. One option is to deliberately ignore opportunity costs. Given uncertainty and ignorance about the consequences of depleting natural capital one might choose to refrain from any marginal decisions and call for the preservation of the remaining totality of certain forms of natural capital. From this perspective, it is better to incur the definite and potentially large costs of preservation in order to prevent the uncertain, but potentially tremendous, costs of depletion. It is argued in Chapter 4, however, that it is better to face the fact that every policy decision for preserving natural capital implies an opportunity cost that has to be balanced against the benefits of preservation. ${ }^{5}$ Deliberately ignoring opportunity costs is tantamount to avoiding the often awkward decisions on how to spend scarce resources for which there are several competing claims. Chapter 4 therefore argues in favour of applying SMS for the forms of natural capital identified as being in need of preservation subject to the condition that preservation costs must not be 'unacceptably high', with preservation costs defined in net terms as opportunity costs minus the expected benefits of preservation.

It is argued in the concluding section of Chapter 4 that such a position is in effect broadly compatible with a moderate deontological or rights-based approach, which obliges the current generation to prevent imposing deliberate harm on the future unless the costs of following this prescription become excessive. Scientific research can help society in providing information on the 
likely benefits and costs of preservation. But it cannot tell society what it should regard as 'unacceptably high' costs. That is, it cannot tell society how risk averse it should be with regard to the depletion of natural capital. The precautionary principle and safe minimum standards imply that opportunity costs may exceed the expected preservation benefits by a certain factor. Economic valuation techniques provide best available information on both benefits and costs. But what are 'unacceptably high' costs is an ethical and political question, not a scientific one.

Chapter 5 assesses whether weak sustainability, as defined in this book, can be measured in practice. A dynamic optimisation or optimal growth model is presented in order to show how 'genuine savings' (GS), the theoretically correct measure of WS, can be derived. The model is set up for the case of a closed economy and the necessary amendments for the open economy case are discussed. Then a series of problems for practical measurements of GS are put forward. The World Bank's (2009a) estimates of GS, the most serious and comprehensive attempt to measure WS so far, are critically assessed. I show that the World Bank's conclusions about the dismal performance of many developing countries with respect to sustainability are largely reversed if the El Serafy method is used for estimating the value of natural resource depreciation instead of the Bank's method. The analysis then turns to the Index of Sustainable Economic Welfare (ISEW) or Genuine Progress Indicator (GPI), an alternative indicator of WS. Again, I show that its conclusions concerning the dismal performance of all examined countries with respect to 'sustainable economic welfare' depend on a few, rather problematic assumptions and, sometimes, methodological errors.

Next, Chapter 6 turns to measuring SS. The analysis in Chapter 4 implies that the second interpretation of SS should be favoured over the first one: it is more sensible to preserve the physical stocks of certain forms of natural capital (at least up to a certain extent). In contrast, preserving natural capital in value terms does not preclude the possibility that certain forms of natural capital providing basic life-support functions are endangered or become irreversibly lost. It is therefore not surprising that all indicators of SS we look at here are either physical indicators or hybrid indicators, which combine the setting of environmental standards in physical terms with monetary valuation.

In the first section on physical indicators, I present the justification and basic idea of the concept of ecological footprints (EF) and the concept of material flows (MF) as the two most important and popular physical indicators of SS. With respect to EF, I show that strong unsustainability fails to be detected if the necessary land area for absorbing carbon dioxide emissions is counted in terms of the required land area for replacing non-renewable with renewable energy resources rather than in terms of land area required for carbon capture via forestry. Since the current rate of carbon dioxide emissions 
is clearly in violation of SS, however, this puts doubt on whether EF can really provide an indicator of SS. With respect to MF, I argue that the call for general reductions in MF is economically inefficient and is not guaranteed to be ecologically effective. Because of the latter, it is also highly doubtful whether the concept of MF really provides an indicator of SS, as suggested by its proponents. If one distinguishes MF according to their potential to threaten critical functions of natural capital, then the concept of MF holds much greater promise, however.

The second section of Chapter 6 looks at hybrid indicators. All of these indicators are inspired by Hueting's (1980) early path-breaking work, which is briefly discussed, and they all set environmental standards for certain forms of natural capital. The concept of sustainability gaps measures the gap between current practice and the defined standards. It also proposes to estimate the costs of achieving the standards, that is of closing the gaps, in monetary terms. This is done under the ceteris paribus assumption in a partial equilibrium framework, where relative prices are assumed to remain unchanged. Two other hybrid indicators - the Greened National Statistical and Modelling Procedures (GREENSTAMP) and the 'Sustainable National Income according to Hueting' - abandon the problematic ceteris paribus assumption and model the costs of achieving the set of environmental standards in a general equilibrium framework. This is their great advantage and disadvantage at the same time as the modelling character makes the indicator difficult to understand as well as highly dependent on model assumptions.

Chapter 7 provides conclusions from the main analysis. More formal derivations of basic principles and results can be found in the accompanying appendices.

\section{NOTES}

I A more neutral term from a gender perspective would be 'human-made' capital. To distinguish this form of capital more clearly from 'human' capital I shall refer to it as 'manmade' capital, however.

2 Capital is defined here broadly as a stock that provides current and future utility. For more detail see Section 2.1, p. 7 .

3 Note that throughout the book I use the terms 'measure' and 'indicator' interchangeably.

4 Value of capital should be interpreted throughout the book in real terms in the sense that the value has to be adjusted for inflation.

5 The usage of the terms 'benefits' and 'costs' might at points be confusing to the reader. Whether something counts as a benefit or a cost depends on the reference point and on the perspective one takes. The benefits of preserving natural capital are the costs of depleting natural capital. Similarly, the benefits of depleting natural capital are the costs of preserving natural capital. 